\title{
PROPAGAÇÃO VEGETATIVA DE PORTA-ENXERTOS PARA CITROS ${ }^{1}$
}

\author{
RENATA APARECIDA DE ANDRADE² \& ANTONIO BALDO GERALDO MARTINS ${ }^{3}$
}

RESUMO - O enraizamento de estacas é um método de propagação assexuada que mantém as características da planta-mãe e incrementa o número de plantas rapidamente, o que é de grande interesse para a citricultura, além de permitir a propagação de materiais na fase juvenil.

A obtenção de porta-enxertos por estaquia é uma prática que pode possibilitar, além da redução do prazo na formação da muda, produção de plantas de menor porte e garantir a uniformidade do pomar. O objetivo do presente trabalho consistiu na observação e comparação da propagação vegetativa, por enraizamento de estacas, de quatro porta-enxertos utilizados na produção de mudas cítricas (Poncirus trifoliata, Citrus volkameriana, Citrumelo Swingle e Citrus limonia), sob a influência de diferentes doses de IBA (ácido indolbutírico). O experimento foi conduzido em câmara de nebulização intermitente, e as estacas foram imersas em soluções com 0; 100; 200 e $400 \mathrm{mg} . \mathrm{L}^{-1}$ de IBA, por um período de 14 horas. Avaliaram-se: porcentagem de sobrevivência; porcentagem de enraizamento; comprimento, e número médios de raízes. Analisando os resultados, conclui-se que: o Citrus volkameriana e o Citrus limonia mostraram resultados superiores aos obtidos para as demais espécies estudadas; a porcentagem de sobrevivência é influenciada pela dose de IBA, pelo porta-enxerto e pela época de coleta das estacas; a porcentagem de enraizamento é influenciada pelas características genéticas do porta-enxerto e época de coleta; o comprimento médio das raízes é influenciado pelo porta-enxerto e época de coleta das estacas; o número médio de raízes é influenciado pela dose de IBA e pelo porta-enxerto.

Termos para indexação: propagação; porta-enxertos; citros; ácido indolbutírico.

\section{VEGETATIVE PROPAGATIONFOR CITRUSROOTSTOCKS}

ABSTRACT - The rooting of cuttings is a method of vegetative propagation that maintains the characteristics of the mother plant and increases the number of plants quickly, which is of great interest for the citriculture, besides allowing the propagation of materials in the juvenile phase.

The obtainment of rootstocks for cutting is a practice that can possible make, besides the reduction of the period in the seedling's formation, the production of plants of smaller load and to guarantee the uniformity of the orchard. The objective of the present work consists in the observation and comparison of the vegetative propagation, for rooting, to four rootstocks used in the production of citric seedlings (Poncirus trifoliata, Citrus volkameriana, Citrumelo Swingle and Citrus limonia), under the influence of different doses of IBA (indolbutiric acid).

The experiment was led in the camera of intermittent nebulization and the cuttings received treatments with $0,100,200$ and $400 \mathrm{mg} . \mathrm{L}^{-1}$ of IBA. It was evaluated: survival percentage; rooting percentage; length and medium number of roots. Analyzing the results it can be conclude that: Citrus limonia and Citrus volkameriana showered better results than the obtained results to others species in study; the percentage of survival is influenced by the dose of IBA and period of the year that the cuttings are collected; the rooting percentage is influenced by the specie of the rootstock and the epoch of collect; the medium length of the roots are influenced by the rootstock and the epoch of collect of the cuttings; the medium number of roots are influenced by the dose of the IBA and the rootstock.

Index terms: propagation; rootstocks; citrus; indolbutiric acid.

\section{INTRODUÇÃO}

O Brasil é o maior produtor de suco concentrado e de laranja fresca, ultrapassando os Estados Unidos. Aárea ocupada com a citricultura aproxima- se de 1 milhão de hectares no território brasileiro e, desse total, 850 mil hectares localizam-se no Estado de São Paulo.

O sucesso na implantação de um pomar de citros está no plantio de mudas de qualidade, sendo, para isso, imprescindíveis a boa formação, o vigor e a sanidade da muda. Tal a importância de mudas de qualidade, que a Secretaria da Agricultura editou três regras para a produção das mesmas, sendo que os viveiros que não atenderem às especificações, deverão ser erradicados: 1) as sementeiras de produção de porta-enxerto de citros somente poderão ser instaladas em ambiente telado à prova de insetos (entrou em vigor a partir de $1^{\circ}-07-2000$ ); 2) a partir de $1^{\circ}-01-2001$, só serão registrados os viveiros para produção de mudas cítricas instalados em ambientes telados à prova de insetos. Os porta-enxertos utilizados nesses viveiros também deverão, obrigatoriamente, ser provenientes de instalações teladas; 3 ) a partir de $1^{\circ}$-01-2003, serão proibidos, em todo o Estado de São Paulo, o comércio e transporte de porta-enxertos e mudas cítricas produzidos em viveiros sem proteção antiinsetos.

As principais características que um porta-enxerto deve apresentar, são: resistência a pragas e doenças das raízes; compatibilidade com as principais copas comerciais; alta produção de frutos e com ótima qualidade dos mesmos; adaptação às condições de solo e clima da área onde será empregado (devendo ser adaptável às mais diferentes situações); grande quantidade de sementes; alta taxa de poliembrionia; facilidade de propagação e enxertia sobre as principais copas comerciais; vigor adequado à indução de bom pegamento dos frutos e de boa maturação; imunidade total ou alta resistência aos patógenos e pragas de importância econômica, incluindo viroses destrutivas e declínios (Carlos et al., 1997; Castle et al., 1993).

Os citros podem ser propagados por quatro métodos: sementes, alporquia, estaquia e enxertia, sendo este último o mais utilizado por apresentar algumas vantagens, entre as quais se pode citar a uniformidade das mudas, uma vez que os porta-enxertos utilizados são poliembriônicos, precocidade no início de produção e aumento na produtividade, além de obterse mudas praticamente idênticas à planta-mãe.

As primeiras espécies cítricas introduzidas no Brasil foram propagadas utilizando-se de sementes. A facilidade deste método norteou a disseminação durante a colonização do Brasil, durante o século XVI. A propagação por sementes, na citricultura mundial, predominou até a metade do século XIX, quando problemas relacionados ao ataque de Phytophthora sp., na Ilha dos Açores (Portugal), determinaram o uso de porta-enxertos tolerantes a estes fungos. Na Espanha, os agricultores perceberam que as plantas provenientes de sementes tardavam muito a entrar em produção e tinham muitos espinhos, que podiam lesionar as frutas, e passaram a adotar a enxertia a partir da segunda metade do século XIX (Carlos et al., 1997).

Na busca pela uniformidade e produtividade, os pomares comerciais de citros são atualmente formados por mudas obtidas por enxertia, mas isso tornou os cultivos vulneráveis a enfermidades típicas de plantas enxertadas, como exocorte, xiloporose e do declínio dos citros (Castro \& Kersten, 1996). Especialmente no caso do declínio, além das laranjeiras enxertadas

\footnotetext{
${ }^{1}$ (Trabalho 185/2002). Recebido: 03/12/2002; Aceito para publicação: 02/04/2003. Parte da Dissertação de Mestrado do primeiro autor.

${ }^{2}$ Eng $^{\mathrm{a}}$. Agr ${ }^{\mathrm{a}}$., Aluna de Pós-graduação em Agronomia - Produção Vegetal - UNESP - FCAV - Depto de Produção Vegetal. Via de acesso Prof. Paulo Donato Castellane, s/n. Cep: 14884-900. Jaboticabal-SP. Tel/Fax: (16)32092668. e-mail: reandrad@fcav.unesp.br.

${ }^{3}$ Eng. Agr., Prof. Doutor - UNESP - FCAV - Departamento de Produção Vegetal. Via de acesso Prof. Paulo Donato Castellane, s/n. Cep: 14884-900. Jaboticabal-SP. Tel/Fax: (16)32092668. e-mail: baldo@fcav.unesp.br.
} 
sobre porta-enxertos tolerantes, plantas produzidas a partir de cascas da própria cultivar-copa parecem tolerantes a este, pela não-utilização do porta-enxerto (Zafarri et al., 1993).

O enraizamento de estacas é um método de propagação assexuada que mantém as características básicas da planta-mãe e incrementa o número de plantas rapidamente, o que é de grande interesse para a citricultura. Muitas espécies de citros podem ser propagadas por estacas (Platt \& Optiz, 1973).

A obtenção de porta-enxertos por estaquia é uma prática que pode possibilitar, além da redução do prazo na formação da muda, a obtenção de mudas tolerantes ao declínio, possibilitando também a utilização de variedades monoembriônicas, com características desejáveis e, ao mesmo tempo, a uniformidade do pomar. Além disso, a produção de porta-enxertos pelo sistema tradicional é sazonal, enquanto a estaquia pode ser realizada, teoricamente, em qualquer época do ano (Zafarri et al., 1993).

De acordo com Grosser*, não há diferença no comportamento entre plantas enxertadas sobre pé-franco ou de estaquia, observando-se apenas, nos seis primeiros meses, um crescimento ligeiramente maior para as primeiras, porém logo se equiparam.

Segundo Komissarov (1968), a época do ano em que a estaquia é realizada, é fator determinante do sucesso, uma vez que está relacionada com o estádio do ramo e com o grau de atividade dos processos fisiológicos das plantas. Os efeitos favoráveis do tratamento com reguladores de crescimento traduzem-se em: estímulo à iniciação radicular; aumento na porcentagem de estacas que formam raízes; aceleração do tempo de formação das raízes, com conseqüente diminuição da permanência das estacas no leito de enraizamento no viveiro (Sampaio, 1989). Quanto ao substrato, dentre as composições diferenciadas favoráveis ao enraizamento, indica-se a vermiculita devido às suas propriedades, como capacidade de absorção de água em cinco vezes sua massa e fácil aeração, insolubilidade em água e solventes orgânicos, $\mathrm{pH}$ levemente alcalino, alta capacidade catiônica e tampão, além de ser um substrato inodoro e atóxico (Gonçalves, 1995).

Aproximadamente $80 \%$ da citricultura encontra-se baseada em plantas enxertadas em limão-cravo, situação esta que perdurou por muitos anos, até que fosse observada a necessidade de diversificação dos porta-enxertos, principalmente após o surgimento da Morte Súbita, doença que tem sido detectada em plantas enxertadas sobre limão-cravo, na maioria dos casos.

Segundo Grosser* e Mourão Filho (2002), os porta-enxertos existentes não possuem as características adequadas àquelas exigidas pela citricultura atual, de modo que vêm desenvolvendo hibridação somática entre espécies, sendo que estes novos porta-enxertos vêm sendo utilizados na forma de estacas.

Frente a esta necessidade de um melhor entendimento acerca da produção de porta-enxertos por estaquia, realizou-se o presente trabalho, objetivando estudar o comportamento de quatro porta-enxertos para citros, avaliando-se o efeito da época de coleta das estacas e do tratamento com diferentes doses de IBA (ácido indolbutírico).

\section{MATERIAL E MÉTODOS}

O experimento foi conduzido em câmara de nebulização intermitente, localizada no ripado, pertencente ao Departamento de Produção Vegetal da FCAV/UNESP, Câmpus de Jaboticabal - SP.

O município de Jaboticabal localiza-se a $21^{\circ} 15^{\prime} \mathrm{S}$ de latitude e $48^{\circ} 18^{\prime} \mathrm{W}$ de longitude, com altitude ao redor de $595 \mathrm{~m}$. O clima da região, baseado na classificação de Köppen, é do tipo Cwa, ou seja, subtropical úmido com estiagem no inverno.

Para a realização do experimento, foram utilizadas estacas herbáceas, com cerca de $12 \mathrm{~cm}$ de comprimento, de Poncirus trifoliata, Citrus volkameriana, Citrumelo Swingle e Citrus limonia, as quais foram imersas em soluções com 0; 100; 200 e 400 mg.L. $L^{-1}$ de IBA (ácido indolbutírico), de acordo com o tratamento, por um período de 14 horas. O material utilizado foi coletado no banco de germoplasma da Fazenda Cambuhy, localizada no município de Matão, Estado de São Paulo. As estacas foram colocadas em bandejas plásticas de dimensões $34 \times 23,5 \times 8,5 \mathrm{~cm}$, tendo como substrato vermiculita de textura média, e foram mantidas sob nebulização intermitente. O experimento foi instalado em épocas distintas do ano (primavera e outono), visando a uma análise do comportamento das estacas quanto ao enraizamento.

O delineamento experimental adotado foi o inteiramente casualizado, tendo-se 4 concentrações de IBA, 4 porta - enxertos, 4 repetições, 10 estacas por parcela, totalizando 160 estacas para cada porta-enxerto. Para a análise dos resultados, utilizou-se do teste de Tukey, ao nível de $5 \%$ de probabilidade.

As avaliações, realizadas 90 dias após a instalação do experimento, foram quanto à: porcentagem de sobrevivência das estacas; porcentagem de enraizamento; comprimento e número médio de raízes.

\section{RESULTADOSEDISCUSSÃO}

Da análise das observações, têm-se que:

- Porcentagem de sobrevivência: a maior porcentagem de sobrevivência foi encontrada para a testemunha ( 0 mg.L $\mathrm{L}^{-1}$ IBA), com $81,80 \%$ de sobrevivência de estacas, diferindo do observado com $100(70,00 \%)$ e 200 mg. L ${ }^{-1}(68,94 \%)$, embora semelhante à dose de $400 \mathrm{mg} . \mathrm{L}^{-1}(71,08 \%)$, como pode ser visto na Tabela 1. Resultados contraditórios foram observados por Roncatto et al. (1999) e Roberto et al. (2001), quando, estudando o efeito do IBA no enraizamento de estacas de laranjeira-'Valência', verificaram que não há influência da dose de IBA no percentual de estacas sobreviventes. Quanto aos porta-enxertos estudados (Tabela 2), os maiores valores para porcentagem de sobrevivência foram encontrados para Citrumelo Swingle $(82,08 \%)$, seguido por Citrus limonia $(73,29)$ e diferindo significativamente do Citrus volkameriana $(70,23)$ e Poncirus trifoliata $(66,25 \%)$. Em relação à época de coleta das estacas, pode-se verificar maior percentual de sobrevivência para aquelas coletadas na primavera $(87,34 \%)$, diferindo significativamente das coletadas no outono $(58,59 \%)$, como mostra a Tabela 3.

TABELA 1 - Influência da dose de IBA para os parâmetros avaliados.

\begin{tabular}{|c|c|c|c|c|}
\hline $\begin{array}{c}\text { IBA } \\
\left(\mathrm{mg}^{-L^{-1}}\right)\end{array}$ & $\begin{array}{c}\% \\
\text { sobrevi- } \\
\text { vência }\end{array}$ & $\begin{array}{c}\% \\
\text { Enraiza - } \\
\text { mento }\end{array}$ & $\begin{array}{l}\text { Comprimen- } \\
\text { to Médio das } \\
\text { Raízes }\end{array}$ & $\begin{array}{c}\text { Número } \\
\text { Médio de Raiz }\end{array}$ \\
\hline 0 & 81,80 a & 47,08 a & 6,02 a & 2,12 \\
\hline 100 & $70,00 \quad b$ & 48,13 a & 6,39 a & 3,23 bc \\
\hline 200 & $68,94 \quad b$ & $41,48 \mathrm{a}$ & 5,83 a & $4,19 \mathrm{ab}$ \\
\hline 400 & $71,08 \mathrm{ab}$ & 40,83 a & 5,33 a & $4,86 \mathrm{a}$ \\
\hline DMS & 11,29 & 10,64 & 1,78 & 1,21 \\
\hline $\mathrm{CV}$ & 23,64 & 36,62 & 46,05 & 51,49 \\
\hline
\end{tabular}

Médias seguidas de mesma letra, na coluna, não diferem significativamente. Teste de Tukey, a $5 \%$ de probabilidade.

TABELA 2 - Comportamento dos quatro porta-enxertos em estudo.

\begin{tabular}{|c|c|c|c|c|}
\hline Porta-enxerto & $\begin{array}{c}\% \\
\text { sobrevi- } \\
\text { vência }\end{array}$ & $\begin{array}{c}\% \\
\text { Enraiza- } \\
\text { mento }\end{array}$ & $\begin{array}{c}\text { Comprimen- } \\
\text { to Médio das } \\
\text { Raízes }\end{array}$ & $\begin{array}{l}\text { Número } \\
\text { Médio } \\
\text { de Raiz }\end{array}$ \\
\hline $\begin{array}{c}C . \\
\text { volkameriana }\end{array}$ & $70,23 \quad b$ & 65,86 a & 8,79 a & 5,19 a \\
\hline P. trifoliata & $66,25 \quad b$ & 3,13 & 0,94 & 0,62 \\
\hline C. limonia & $73,29 \mathrm{ab}$ & 60,28 a & $7,09 \mathrm{ab}$ & $4,74 \mathrm{ab}$ \\
\hline C. Swingle & 82,08 a & $48,26 \quad \mathrm{~b}$ & $6,73 \quad b$ & 3,85 \\
\hline DMS & 11,29 & 10,64 & 1,78 & 1,21 \\
\hline $\mathrm{CV}$ & 23,64 & 36,62 & 46,05 & 51,49 \\
\hline
\end{tabular}

Médias seguidas de mesma letra, na coluna, não diferem significativamente. Teste de Tukey, a 5\% de probabilidade.

\footnotetext{
* Grosser, J.W. University of Florida. Institute of Food and Agricultural Sciences, Citrus Research and Education Center, Lake Alfred, FL, 33850, USA. 23 de outubro de 2002. $7^{\circ}$ Seminário Internacional de Citros - Melhoramento. Bebedouro-SP,Brasil.
} 
TABELA 3- Influência da época de coleta das estacas nos parâmetros avaliados.

\begin{tabular}{ccccc}
\hline $\begin{array}{c}\text { Época } \\
\text { do ano }\end{array}$ & $\begin{array}{c}\text { avaliados. } \\
\text { sobrevi- } \\
\text { vência }\end{array}$ & $\begin{array}{c}\% \\
\text { Enraiza- } \\
\text { mento }\end{array}$ & $\begin{array}{c}\text { Comprimen- } \\
\text { to Médio das } \\
\text { Raízes }\end{array}$ & $\begin{array}{c}\text { Número } \\
\text { Médio } \\
\text { de Raiz }\end{array}$ \\
\hline $\begin{array}{c}\text { Prima- } \\
\text { vera }\end{array}$ & 87,34 a & 56,11 a & 6,52 a & 3,75 a \\
\hline Outono & $58,59 \quad$ b & $32,66 \quad$ b & $5,26 \quad$ b & 3,45 a \\
\hline DMS & 6,05 & 5,70 & 0,95 & 0,65 \\
\hline CV & 23,64 & 36,62 & 46,05 & 51,49 \\
\hline
\end{tabular}

Médias seguidas de mesma letra, na coluna, não diferem significativamente. Teste de Tukey, a $5 \%$ de probabilidade.

- Porcentagem de enraizamento: não foi observada diferença significativa para este parâmetro em relação à dose de IBA (Tabela 1). Resultados semelhantes foram encontrados por Prati et al. (1999), em lima-ácida 'Tahiti', que observaram não ser necessário o emprego de reguladores de crescimento para o enraizamento de estacas. A variabilidade genética entre as espécies estudadas foi marcante na indução radicular, como pode ser visualizado na Tabela 2, onde há diferenças quanto às respostas, sendo o Citrus volkameriana que apresentou os melhores resultados. Essa diferença varietal também foi relatada por Prati et al. (1999), que observaram um enraizamento de $96 \%$ para a limaácida 'Tahiti' e 0\% para a laranjeira 'Valência'. Quanto à época do ano, as estacas coletadas na primavera apresentaram $56,11 \%$ de enraizamento, diferindo significativamente daquelas coletadas no outono (Tabela 3) e concordando com Hartmann et al. (1990), os quais relataram que as estacas coletadas em um período de crescimento vegetativo intenso (primavera/verão) apresentam-se mais herbáceas, com melhor capacidade de resposta, e as colhidas em um período de repouso vegetativo ou de dormência (outono/inverno) apresentam-se mais lignificadas e, de modo geral, tendem a enraizar menos.

- Comprimento médio das raízes: não se verificou influência da dose de IBA no comprimento de raiz (Tabela 1), o mesmo não ocorrendo com os porta-enxertos, sendo que, como no caso anterior, o Citrus volkameriana foi o que apresentou maior valor para este parâmetro $(8,79 \mathrm{~cm})$, seguido por Citrus limonia, Citrumelo Swingle e Poncirus trifoliata, com 7,09; 6,73 e 0,94 cm, respectivamente (Tabela 2). Similarmente, Santos et al. (1987) e Villas Boas et al. (1987), em estudo sobre o enraizamento de outras espécies de citros, verificaram uma diferença na resposta ao enraizamento em função da espécie. Quanto à época do ano, como no caso anterior, as estacas coletadas na primavera apresentaram maiores valores em relação àquelas coletadas no outono, como pode ser visualizado na Tabela 3 .

- Número médio de raiz: a maior dose de IBA, ou seja, 400 $\mathrm{mg.L} \mathrm{L}^{-1}$, foi a que proporcionou maior número médio de raízes, possibilitando a formação de um sistema radicular mais efetivo, diferindo dos tratamentos com 0 e $100 \mathrm{mg} . \mathrm{L}^{-1}$ de IBA (Tabela 1). Resultados similares foram encontrados por Roncatto et al. (1999), que verificaram um incremento no número de raízes por estaca com a utilização de IBA, indicando sua eficiência em laranjeira Valência. Em relação aos portaenxertos, o Citrus volkameriana e Citrus limonia foram os que apresentaram maiores valores para esta variável. A ocorrência de diferença varietal para esta variável foi também observada por Prati et al. (1999), em estudo realizado para avaliar o enraizamento de estacas das laranjas 'Pêra' e 'Valência' e da lima-ácida 'Tahiti', não verificando, entretanto, diferença em função da dose de regulador empregada. Não foi observada diferença significativa para esta variável em relação à época do ano.

\section{CONCLUSÕES}

Para as condições em que o experimento foi realizado, pode-se concluir que: o Citrus volkameriana e o Citrus limonia mostraram resultados superiores aos observados para as demais espécies em estudo; a porcentagem de sobrevivência é influenciada pela dose de IBA, pelo porta-enxerto e pela época de coleta das estacas; a porcentagem de enraizamento é influenciada pela espécie de porta-enxerto e época de coleta das estacas, o comprimento médio das raízes é influenciado pelo porta-enxerto e pela época de coleta das estacas, e o número médio de raízes é influenciado pela dose de IBA e pela espécie de porta-enxerto utilizada.

\section{REFERÊNCIASBIBLIOGRÁFICAS}

CARLOS, E.F.; STUCHI, E.S.; DONADIO, L.C. Porta-enxertos para a citricultura paulista. Jaboticabal: FUNEP, 1997. 47p. (Boletim Citrícola, 1)

CASTLE, W.S.; TUCKER, D.P.H.; KREZDORN, A.H.; YOUTSEY, C.O. Rootstocks for Florida citrus. Gainesville: Institute of Food and Agricultural Sciences - University of Florida, 1993. 92p.

CASTRO, A.M.; KERSTEN, E. Influência do anelamento e estiolamento de ramos na propagação da laranjeira Valência (Citrus sinensis (L.) Osbeck) através de estacas. Scientia Agrícola, Piracicaba, n.53, v.2/ 3, p.199-203, 1996.

GONÇALVES, A.L. Substratos para produção de mudas de plantas ornamentais. In: MINAMI,K. Produção de mudas de alta qualidade em horticultura. São Paulo: T.A. Queiroz, 1995. p.107-115.

HARTMANN, H.T.; KESTER, D.E.; DAVIES JUNIOR, F.T. Plant propagation: principles and practices. 5. ed. Englewood Cliffs:Prentice Hall, 1990.647p.

KOMISSAROV, D.A. Biological basics for the propagation of wood plants by cuttings. Jerusalem: IPST Press, 1968. 250p.

MOURÃO FILHO, F.A.A. Hibridação somática para melhoramento de porta-enxertos em São Paulo. In: Seminário Internacional de Citros, 7., 2002. Bebedouro-SP. Palestras... Bebedouro: Estação Experimental de Citricultura de Bebedouro, Sociedade Brasileira de Fruticultura, 2002.p.134-140.

PLATT, R.G.; OPTIZ, K.W. Propagation of Citrus. In: REUTHER, W. The citrus industry. Berkeley: University of California Press, 1973. v.3, p.1-47.

PRATI, P.; MOURÃO FILHO, F.A.A.; DIAS, C.T.S.; SCARPARE FILHO, J.A. Estaquia semilenhosa: um método rápido e alternativo para a produção de mudas de lima-ácida 'Tahiti'. Scientia Agricola, Piracicaba, v.56. n.1.jan/mar. p.185-190, 1999.

ROBERTO, S.R.; PEREIRA, F.M.; CAETANO, A.C. Efeito do ácido indolbutírico no enraizamento de estacas herbáceas de laranjeira 'Valência' (Citrus sinensis [L.] Osbeck). Revista Brasileira de Fruticultura, Jaboticabal-SP, v.23, n.1, p. 206-208. Abril, 2001.

RONCATTO, G; GONÇALVES, E.D.; DUTRA, L.F.; KERSTEN, E. Influência do sombreamento das plantas e do ácido indolbutírico no enraizamento de estacas de laranjeira (Citrus sinensis (L.) Osbeck) Cv. Valência. Revista Cientifica Rural. v.4, n.2, p.60-65, 1999.

SAMPAIO, V.R. Enraizamento de estacas de laranja 'Pêra' (Citrus sinensis Osbeck). In: Congresso Brasileiro de Fruticultura, 10., 1989, Fortaleza-CE. Anais... Fortaleza-CE:SBF, 1989. p.126-30.

SANTOS, R.F.A.; VILLAS BOAS, R.M.F.; SALIBE, A.A. Estudos sobre o enraizamento de estacas de citros com aplicação de agentes de efeito hormonal. In: Congresso Brasileiro de Fruticultura, 1987. Campinas-SP. Anais... v.1, p.387-393.

VILLAS BOAS, R.M.F.; SANTOS, R.F.A.; SALIBE, A.A. Enraizamento de estacas de diferentes espécies de citros. In: Congresso Brasileiro de Fruticultura. Campinas-SP. 22 a 27 de novembro. Anais... v.1. p.367373. 1987.

ZAFARRI, G.R.; KOLLER, O.L.; STUKER,H. Efeito do ácido 2,4 diclorofenoxiacético e do ácido indolbutírico sobre o enraizamento de estacas de citros. Revista Brasileira de Fruticultura, Cruz das Almas-BA, v.15, n.2, p.39-44. Agosto, 1993. 